\title{
MICROALGAE AND THE FACTORS INVOLVED IN SUCCESSFUL PROPAGATION FOR MASS PRODUCTION
}

\author{
ALIFFIKRI RAMLEE ${ }^{3}$, NADIAH W. RASDI*1,2, MOHD EFFENDY ABD WAHID ${ }^{1}$ AND \\ MALINNA JUSOH ${ }^{3}$
}

${ }^{1}$ Faculty of Fisheries and Food Sciences, ${ }^{2}$ Institute of Tropical Biodiversity and Sustainable Development, ${ }^{3}$ Faculty of Science and Marine Environment Universiti Malaysia Terengganu, 21300 Kuala Nerus, Terengganu Malaysia.

*Corresponding author: nadiah.rasdi@umt.edu.my

Submitted final draft: 14 Jun 2020 Accepted: 1 July 2020

http://doi.org/10.46754/jssm.2021.04.003

\begin{abstract}
Recently, microalgae have been regarded as useful organisms worldwide due to their potential for extensive application in renewable energy, aquaculture, biofuel and pharmaceuticals. Different species of microalgae have drawn significant interest because of their biological and chemical composition, which could potentially be useful in developing new applications in the aquaculture, biofuel and pharmaceutical industries. Furthermore, various culture techniques have been developed based on the species and environmental condition to ensure its mass production. Although microalgae are feasible sources for a successful biological product, limitations and challenges remain, which need to be solved with the innovation of new alternative technology in culturing and producing successful mass cultures. In this review, several current microalgae species production methods will be discussed based on their applications, and biological and chemical compositions, which are influenced by their growth parameters.
\end{abstract}

Keywords: Microalgae, aquaculture, biological, chemical composition, growth parameter.

\section{Introduction}

Microalgae are defined as microscopic single cells, which may be prokaryotic, such as cyanobacteria (chloroxybacteria), or eukaryotic. They are similar to green algae (Chlorophyta). Known as a class of photosynthetic organisms, microalgae are typically found in freshwater aquatic and marine habitats, including rivers, lakes, wastewater, oceans and estuaries. The growth of algae is possible in various conditions, temperature levels, salinities, $\mathrm{pH}$ values and light intensities. Alga can grow on its own or symbiotically with other aquatic organisms (Barsanti et al., 2008).

Some microalgae have high carbon compound content, which may be utilized for new organic-based products, including biofuels, health supplements, pharmaceuticals, and cosmetics (Das et al., 2011). Furthermore, largescale microalgae cultivation can contribute to the development of a sustainable industry for biomass production and the development of cost-effective high-value products. Many species of microalgae, such as Chlorella vulgaris, Tetraselmis suecica and Isochrysis galbana possess the potential for large-scale cultivation despite the insufficient information to run commercial trials ( $\mathrm{Xu}$ et al., 2009). A high amount of microalgae biomass is required to be on a par with the feedstock for sustainable production. According to Cheng et al. (2019), the growth and biomass production of microalgae is significantly dependent on cultivation conditions and concentration of microalgae, which can be manipulated based on their optimum culture parameter.

Moreover, the concentration of microalgae in a solution is an important element which quantifies the productivity for biomass production. Meanwhile, cell density is generally defined as the concentration of microalgae in a medium in terms of the number or mass of cells per unit of volume, which is essential in determining microalgae growth (Pahija et al., 2019). Therefore, the attraction of microalgae as a sustainable and renewable bio-product has encouraged a new focus on biomass cultivation. Improvements in growth, culture techniques and genetic engineering can be utilized to enhance their potential as a future source of bio-products. 


\section{Microalgae as a Bioproduct}

Different green algae species have been utilized as food for decades (Jensen et al., 2001). The cultivation of microalgae started when it was realized there could be a lack of sources for protein-rich foods for a rapidly growing world population (Borowitzka et al., 1988). Based on previous research, the first large-scale culture microalgae were the Chlorella species, which were reported to be used for commercial purposes in Japan in the 1960s (Iwamoto, 2004). Over the last few decades, algae culturing has expanded to new products, such as food and feed, biofuels, and biopharmaceuticals, along with the use of natural products in algal extracts in cosmetics and medicines (Luiten et al., 2003). Microalgae produce a wide range of other commercially valuable products, including essential vitamins for people and animals, and aquaculture purposes (Cuellar et al., 2011). In addition, microalgae contain important types of medicinally essential polysaccharide pigments, such as chlorophyll, $\beta$-carotene and other carotenoids, phycobiliproteins and astaxanthin (Guil et al., 2004). Previous work from Liang et al. (2004) found that microalgae had been used as nutrients, colouring agents and additives in a variety of food products. Microalgae can, therefore, be a promising source of bioproducts that can be applied to new production through mass cultivation. Microalgae must be modified and enhanced in order to produce a new type of algae-based product that can be used as a food for both humans and animals.

\section{Current Algae Production}

Despite the wide range of potential applications of microalgae for aquaculture and other useful products, the production of microalgae has not been fully commercialised due to several issues, including failure to overcome physiological stresses, nutrient deficiencies, high cost of mass production and failure to identify the suitable conditions mass microalgae cultivation (Mallick et al., 2016). Furthermore, some microalgae either do not produce important metabolites or produce them in small amounts under normal conditions. Some microalgae also do not fully adapt to environmental changes like $\mathrm{pH}$, temperature, light, carbon dioxide concentration, salinity and nutrients (Molina et al., 2003).

To achieve the highest microalgae productivity in a cost-effective manner, the selection of cultivation method is crucial. Environmental factors play an important role in controlling the growth phases of microalgae, but they can be cultured through different methods under various conditions. (Campbell et al., 2011). Environmental source of nutrients and light are needed to convert the absorbed water and $\mathrm{CO}_{2}$ into biomass through photosynthesis (Ozkurt, 2009), leading to the creation of various products including cell components or storage materials, and vary from $20 \%$ to $50 \%$ of total biomass (Chisti, 2007). Nitrogen and phosphorus are the major nutrients required by the algae. Nitrogen is a basic component for the development of proteins and nucleic acids, while phosphate is a vital component of DNA and RNA, which are essential macromolecules for all living cells. (Juneja et al., 2013).

Algae growth also requires macronutrients, including $\mathrm{Na}, \mathrm{Mg}, \mathrm{Ca}$, and $\mathrm{K}$; micronutrients, including $\mathrm{Mo}, \mathrm{Mn}, \mathrm{B}, \mathrm{Co}, \mathrm{Fe}$, and $\mathrm{Zn}$; and other trace elements. Additionally, wastewater from aquaculture and agriculture is a good source of nutrients for microalgae cultivation. Although different species of microalgae will go through different growth phases based on their needs for growth media in biomass production, the primary requirements are the same for almost all species (Campbell et al., 2011).

\section{Algae Culturing}

Generally, the growth of microalgae may be separated into four phases - lag, log or exponential phase, stationary phase, and finally death (Moazami et al., 2012). The initial lag phase is when the microalgae adapts to their surroundings, including the medium, $\mathrm{pH}$, temperature, and lighting. Subsequently, the microalgae begin to undergo active cell division, which is followed by an exponential increase in the biomass of the culture (Chisti, 2007). Following that, the stationary phase takes place, 
which halts the increase in the biomass due to the equal rate of the cell division and death (Jusoh et al., 2020). This phase mainly occurs as a result of the depletion of nutrients in the medium (Paes et al., 2016). Consequently, the microalgae death rate would be higher compared to the rate of the cell division. Microalgae can be cultured through different methods under various conditions and the most important parameters in algae culturing is the type of growth system (Khan et al., 2018), which should be designed according to the species and the purpose of culture.

On a large scale, although algae can be cultured in low-cost open ponds, which are ideal for commercial production, this method is easily contaminated by surrounding organisms (Borowitzka et al., 2013). Bioreactors consist of continuous or batch culture facilities but are relatively high cost. The requirements for constant growth restricts this method to indoor facilities and is only feasible for relatively small-scale production (Cragg, 2000). Some algae species undergo significant growth in heterotrophic culture (Morales et al., 2017), while in commercial cultivation, the culturing of microalgae in wastewater is ideal for water treatment and biomass production. Instead of freshwater, using seawater for microalgae culturing is ideal for algae growth as it reduces production cost. Marine water is a potential media for microalgae culture as it reduces nutrient preparation cost and increases the production of lipids and other useful byproducts in microalgae biomass (Park et al., 2018). Most recently, ocean cultivation systems for commercial-scale production of algae have gained considerable attention due to its advantages, such as the mixing of the culture by ocean waves, utilisation of dissolved nutrients, and large area availability, which could reduce culturing and maintenance cost (Kim et al., 2016).

\section{Factors in Microalgae Cultivation}

\section{Light}

Light intensity is one of the major factors in microalgae cultivation. The photosynthesis of microalgae is influenced by light radiance and intensity, which affect the biochemical composition of microalgae and biomass yield (Krzemińska et al., 2014). Growth rate and biomass productivity are predicted as the function of light in the microalgae culture system (Huesemann et al., 2013). Furthermore, algae species vary in terms of light requirements for optimum growth and biomass production, and the rapid growth of microalgae would not take place under extremely low and high light intensities (Mata et al., 2010). Therefore, optimal light intensity needs to be observed in each species of alga to maximise $\mathrm{CO}_{2}$ absorption with a minimum rate of photorespiration and photoinhibition (Ye et al., 2012). A specific duration of light and dark periods needs to be set for algal photosynthesis. Light is also required for the synthesis of ATP (adenosine triphosphate) and NADPH (nicotinamide adenine dinucleotide phosphate), which stimulates the dark reactions of photosynthesis that produce carbon (Cheirsilp \& Torpee 2012).

Previous research by Khoeyi et al. (2011) illustrated the differences between growth rate and biomass production, which were observed through the growth of the same algae species under different light intensities and for specific durations. Research by Jacob et al. (2009) found that decreased light intensities and duration would reduce microalgae growth rate and biomass yield. Most previous research has illustrated that the suitable duration of light and dark periods for algae growth are 16 and 8 hours respectively (Gunawan et al., 2018; Asfouri et al., 2019). Furthermore, appropriate light intensity, penetration, fixed distribution, and duration are essential in the cultivation of microalgae to avoid photo oxidation and growth inhibition (Carvalho, 2010). LED lights and fluorescent tubes could provide adequate light in algae cultivation ( $\mathrm{Wu}, 2016)$. It was also observed by Mata et al. (2010) that microalgae cultivation under $12000 \mathrm{~lx}$ for 12 hours of daylight, produced a higher biomass yield, while the biomass decreased with the reduction of light intensity. Apart from that, a study by Khan et al. (2016) demonstrated that Microcystis 
aeruginosa contributed to maximum biomass and carbohydrates productivity with red LED light at approximately $5000 \mathrm{~lx}$. Daliry et al. (2017) reported that the Chlorella vulgaris produced maximum lipid production and highest growth rate at 5000-7000 1x. Therefore, photo inhibition could be prevented by increasing the light intensity through continuous illumination and mixing the light source of the culture to influence the growth and lipid production of microalgae.

Other than that, a study by Hubble and Harper (2001) found that microalgae cultures could have a self-shading effect. Self-shading happens when a high density of microalgae cells absorb the light, denying illumination to cells deeper in the culture (González et al., 2019). According to Sorejo et al. (2020) the negative effect of self-shading could be overcome by giving the culture a good mixing or aeration. Other than that, Mata et al. (2010) also reported that an aerated culture of microalgae under uniform light intensities for 12 hours produced a higher biomass yield and prevented self-shading of the cells.

Maynardo et al. (2015) found that heat generated by high light intensity will increase the temperature and can cause a decline in growth rate. The optimum growth of common green microalgae such as Chlorella $\mathrm{sp}$, Tetraselmis sp and Nannochloropsis sp will be at light intensity of $15-150 \mu \mathrm{mol}$ of photons, which is between 1,000 and 10,000 lx (Simionato et al., 2013). Therefore, to avoid high light intensity, flashing lights or adjusting the phototropic period for the 12-hour light and dark periods may obliquely control the light intensity which indirectly affects temperature (Suh et al., 2003).

\section{Temperature}

Temperature plays a major role in the growth of microalgae by influencing photosynthesis. Essentially, the optimal temperature for exponential growth varies according to species, while deviating more or less from this optimal point could affect growth and activity (Bechet et al., 2017). The optimum temperature range for most algal species is from $20^{\circ} \mathrm{C}$ to $30^{\circ} \mathrm{C}$ (Singh et al., 2015). Thermophilic algae, including Anacystis nidulans and Chaetoceros sp, could endure temperatures of up to $40^{\circ} \mathrm{C}$ (Covarrubias et al., 2016). Non-optimal temperature could result in high biomass loss in microalgae, particularly in outdoor culture systems (Alabi et al., 2009; Hu et al., 2006).

Temperature is an important factor in large-scale cultivation as the algae experiences significant temperature changes over time (Bechet et al., 2010). Low temperature affects photosynthesis through reduced carbon assimilation, while higher temperatures inhibit cell size and respiration (Khan et al., 2018). As the decline in photosynthesis results in decreased growth rate, temperature is a major factor of algal growth and biomass production through its influence on the assimilation of $\mathrm{CO}_{2}$. Temperature could also be used as a stress treatment to induce the production of valuable metabolites (Moller et al., 2000). Temperatures from $27{ }^{\circ} \mathrm{C}$ to $31{ }^{\circ} \mathrm{C}$ are optimum for several microalgae species. It was previously shown that a culture of Chlorella vulgaris led to further production of carbohydrates and lipids under $25^{\circ} \mathrm{C}$ instead of $30^{\circ} \mathrm{C}$ (Converti et al., 2009).

\section{Nutrients}

Nutrient requirements for microalgae vary between species. However, the basic nutrients for growth are the same - nitrogen, phosphorus, and carbon (Juneja et al., 2013). Notably, some marine microalgae species also require silicate as a macronutrient. The presence of macronutrient during cultivation significantly affects growth rate and oil content of the algal biomass (Lardon et al., 2009; Solovchenko et al., 2008). Research by Aslan et al. (2006) found that the growth of Chlorella $s p$ decreased as concentrations of nitrogen and phosphorus are reduced from $31.5 \mathrm{mg} / \mathrm{l}$ and $10.5 \mathrm{mg} / \mathrm{l}$ respectively and another study from Raehtz et al. (2009) found lipid production increased under conditions insufficient of phosphorus, which is attributed to the breakdown of cell membrane phospholipids into neutral lipids in order to obtain phosphorus. 
The other major nutrients to be supplied were carbon, which is important for photosynthesis in microalgae growth and also contributes to a shift in microalgae nutrient composition. According to Juneja et al. (2013), carbon can be utilized in the form of $\mathrm{CO}_{2}$ in the water, depending on $\mathrm{pH}$, temperature and nutrient content. Previous research from Riebesell et al. (2000) said polyunsaturated fatty acid (PUFA) in Emiliania huxleyi was increased in lower $\mathrm{CO}_{2}$ concentration, whereas fatty acid was increased in higher $\mathrm{CO}_{2}$ levels. The high amount of fatty acid in Dunaliella salina was also observed to impact the culture condition due to the increased $\mathrm{CO}_{2}$ (Muradyan et al., 2004). Si (silicate) is also required as a macronutrient for diatom algae (Flynn, 2020). According to Martin et al. (2000) silicate incorporated for development of outer walls of algae cell, which acts as pressure vessels to prevent the enlargement of cells when water enters. Research by Hemalatha et al. (2014) found that growth and biochemical composition of Chaetoceros simplex were significantly modified when grown on the media added with silicate $(\mathrm{Si})$. Other than that, the diatom Nitzschia perspicua can accumulated additional carbohydrate and lipids without significantly affecting the growth rate by changing the concentration of $\mathrm{Si}$ in the media culture (Jiang et al., 2015). Although Mo, K, $\mathrm{Co}, \mathrm{Fe}, \mathrm{Mg}, \mathrm{Mn}, \mathrm{B}$, and $\mathrm{Zn}$ are only required in trace amounts in algae cultivation, these micronutrients have a significant impact on microalgae growth due to their influence on many enzymatic activities ( $\mathrm{Hu}$ et al., 2006; Gardner et al., 2017).

Usually, inorganic nitrogen and phosphorus are absorbed as nitrates and phosphates. Urea can also be a cost-effective replacement for other inorganic nitrogen sources. For the largescale cultivation of microalgae, environmental $\mathrm{CO}_{2}$ must be used as a carbon source, which is not only low in cost, but has the benefit of sequestering $\mathrm{CO}_{2}$. The lack of this nutrient highly affects the microalgae growth and results in low biomass (Ito et al., 2012). Therefore, proper nutrition of microalgae is essential for rapid growth in commercial production.

\section{Mixing}

In microalgae cultivation, mixing and aerating are crucial to distribute nutrients, air and $\mathrm{CO}_{2}$. The penetration and uniform spread of light inside the culture and the settling of biomass, which leads to aggregation, could also be promoted through aerating and mixing (Show et al., 2017). Although other requirements are fulfilled without mixing, significant reduction of biomass productivity will occur. Therefore, microalgae cultures must be continuously mixed to expose all microalgae cells to light during their cultivation. Additionally, a proper mixing system in cultivation does not only enable nutrient dissolution and light penetration into the culture, but it also leads to efficient gaseous exchange (Zeng et al., 2011).

\section{Media pH}

Media $\mathrm{pH}$ plays an important role in cell growth and biomass production for microalgae. Previous studies suggest that the optimal $\mathrm{pH}$ for marine algae is 7.9-8.3 and 6.0-8.0 for freshwater microalgae (Pandey et al., 2010; Ying et al., 2014). The optimal $\mathrm{pH}$ range may vary widely based on the natural habitat of microalgal (Prokop et al., 2015). The maximum growth rate for the Spirulina plantensis was observed at $\mathrm{pH} 8.0$, followed by $\mathrm{pH} 9.0$ and then $\mathrm{pH} 7.0$ suggesting that moderate alkalinity was necessary (Fagiri et al., 2013). A study by Khalil et al. (2010) found that Chlorella ellipsoidea could grow in $\mathrm{pH} 4-10$. Bartley et al. (2014) investigated the influence of $\mathrm{pH}$ on growth and lipid accumulation in Nannochloropsis salina and found that the highest growth rates were at $\mathrm{pH}$ 8.0-9.0. The changes in $\mathrm{pH}$ levels may occur due to the changes in the dissolved $\mathrm{CO}_{2}$, which are generated by changing $\mathrm{CO}_{2}$ input concentrations or adjusting $\mathrm{CO}_{2}$ uptake by the cells due to growth rate or increased biomass (Prokop et al., 2015). Besides, high $\mathrm{CO}_{2}$ levels are also present, such as the $\mathrm{pH}$ levels found in gas exchange by the media $\mathrm{pH}$ towards acidic conditions. Furthermore, media $\mathrm{pH}$ usually decreases due to $\mathrm{CO}_{2}$ dissolution, which would gradually increase with further growth of cell 
(Kao et al., 2014; Valdés et al., 2012). Apart from that, the uptake of nutrients by the microalgae, including ammonia, nitrate, and phosphates, may also contribute to significant $\mathrm{pH}$ changes in the medium. As it was found that the significant $\mathrm{pH}$ rise occurred with the increasing biomass concentration, it was concluded that careful management is critical to avoid alteration of $\mathrm{pH}$ in the cell growth stages, which can influence the biomass of microalgae (Bajpai et al., 2013).

\section{Salinity}

Culturing microalgae under optimum salinity may have an impact on the biomass composition of certain algae species. It was found by Renaud et al. (1991) and Elfituri, (2018) that the gross chemical and fatty acid compositions of Isochrysis sp, Nannochloropsis oculata, and Nitzschia sp were distinguishable from one another under different salinities. Furthermore, experiments conducted on marine diatoms (Amphora sp, Navicula sp, and Cymbella sp) and a cyanobacteria (Oscillatoria $\mathrm{sp}$ ) at different salinities resulted in diatom growth, which was significantly higher at $35 \mathrm{ppt}$ than at lower salinity (Khatoon et al., 2010). Although the cyanobacteria displayed a higher growth at 25 ppt, the diatom growth in terms of protein and lipid composition ranged from $15 \mathrm{ppt}$ to $25 \mathrm{ppt}$ in low salinities, which was significantly higher (Khatoon et al., 2016). Meanwhile, research by Castro Araujo and Tavano Garcia (2005) demonstrated that although carbohydrates were enhanced under high salinity, the content of lipids and protein were decreased in Chaetoceros sp. It was also recorded by Rao et al. (2007) that the growth and biochemical composition of Botryococcus braunii, including hydrocarbon, carbohydrate, fatty acid, and carotenoids, were influenced by salinity. However, salinity stresses could also be influenced by species and strains (Shetty et al., 2019). Overall, more observations should be conducted to ensure that the optimum salinity of certain species could be identified for the optimum biomass production of microalgae.

\section{Algae Organic-Based Byproduct}

\section{Carotenoids}

Carotenoids refer to the yellow, orange and red organic pigments produced by plants, algae and several bacteria and fungi (Linnewiel et al., 2016). More than 750 structurally defined carotenoids are discoverable from nature, such as land plants, algae, bacteria, including cyanobacteria and photosynthetic bacteria, archaea, fungus, and animals (Britton et al., 2004). Carotenoids are the essential bio compounds which play an important role in the production of food, feed cosmetics, and biopharma around the world (Henriquez et al., 2016).

Algae synthesise various types of pigments, resulting in important biological activities, which have gained significant commercial interest. Among the most useful pigments produced by microalgae are the phycobiliproteins, phycocyanin, phycoerythrin, $\beta$-carotene, lutein and astaxanthin (Zhang et al., 2016). According to Perez et al. (2011), phycobiliprotein pigments are mainly used in microscopy as fluorescent agents, while phycocyanin and other pigments from red algae exhibit antioxidant and antiinflammatory effects, which are suitable to be used in the food and cosmetic products (Kumar et al., 2014). The microalgae Dunaliella salina produces the carotenoid pigment $\beta$-carotene in quantities approximately $10 \%$ to $14 \%$ of its dry mass. The carotenoid pigment is important in vision and the immune system due to its relation to vitamin A (Chidambara et al., 2005). Another important carotenoid pigment is astaxanthin, which is present in Haematococcus pluvialis. This microalgae species, which has been identified as the astaxanthin-rich source, produces $4 \%$ to $5 \%$ astaxanthin per dry biomass (Sathasivam et al., 2017). Due to the strong antioxidant activity of the carotenoids, they are therapeutic in oxidative stress-related diseases and main organic pigment uses for the treatment of diabetes, ageing, cancer, obesity and stroke (Linnewiel et al., 2016). Additionally, $\beta$-Carotene protects membrane lipids from peroxidation, which is linked with various 
severe and lethal diseases including cancer, cardiovascular disease, Parkinson's disease, and atherosclerosis (Chidambara et al., 2005).

\section{Polyunsaturated Fatty Acids (PUFA)}

Fatty acids (FAs) are the most important components of marine microalgae sources as they are structurally diverse and have gained importance due to their taxonomic specificity (Sahu et al., 2013; Mathimani et al., 2018). Among the fatty acids, polyunsaturated fatty acids (PUFA's) have more than one double bond in their long carbon chain, and longchain fatty acids are broadly known for their beneficial effects on human health (Guihéneuf \& Stengel, 2013). The nutritional value of microalgae is mainly related to their essential

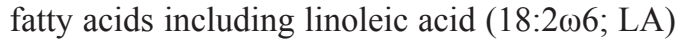
and $\alpha$-linolenic acid (18:3 03 ; ALA) contents (Liang et al., 2004). Various microalgae species including Porphyridium cruentum, Arthrospira platensis, Odontella sp, Isochrysis galbana had been explored for their ability to synthesise these valuable fatty acids (Khan et al., 2018). To be specific, the previous study by Guedes (2010) revealed that large quantities of PUFA were produced by Pavlova lutheri. Eicosapentaenoic acid (EPA) and docosahexaenoic acid (DHA) are the most important PUFA produced by several microalgae species, which could be promising sources and the alternatives to fish oils, which are available in limited quantity and unable to fulfil the demands of EPA and DHA (Hamilton et al., 2014). In the freshwater and marine food chain, DHA and EPA are incorporated by microalgae under various culture conditions (AdarmeVega et al., 2012). Various microalgae species including Nannochloropsis sp, Tetraselmis sp, Chaetoceros sp, Isochrysis sp and Thalassiosira sp produce sufficient amounts of DHA and EPA which are responsible for the development of various bivalve larvae (Kumar et al., 2019) and previous research from Peltomaa et al. (2017) also mentioned that Nannochloropsis $\mathrm{sp}$ is evaluated as the most notable strain in the large volume DHA and EPA production. Other than that, recent studies also show that
Phaeodactylum tricornutum gained attention as a potential source of EPA and DHA production (Koller et al., 2014), but the commercial-scale production of microalgae for EPA and DHA products cannot be achieved because several issues lead to low product yields (Hamilton et al., 2016). As a crucial fatty acid, EPA plays an important role in the regulation of biological functions as a treatment for human diseases such as heart and inflammatory diseases (Wen \& Chen, 2003), while DHA acts as a protection against neuro diseases such as Alzheimer, Parkinson and multiple sclerosis (Shanab et al., 2018).

\section{Proteins and Enzymes}

Some proteins, peptides and amino acids are necessary for cells and tissues to perform their normal activities. Therefore, if the human body is unable to synthesise these components, they must be obtained from an external source, which is usually food. Various species of microalgae produce a higher quantity of various essential amino acids and proteins, which could be utilised in food and used for protection against several diseases. Some species of microalgae could produce the same amount of proteins as other rich sources of proteins (Gouveia et al., 2008). Bleakley et al. (2017) found that protein from microalgae consists of branched-chain amino acids, which are required for various functions of the body, especially in relation to muscle protein health. Furthermore, antioxidant peptides derived from hydrolysed Pavlova lutheri biomass and microbial hydrolysis of Chlamydomonas sp appear to suppress Helicobacter pylori-induced carcinogenesis (Hayes et al., 2018). Isochrysis galbana produces the vital enzyme carbonic anhydrase, which plays a crucial role in converting $\mathrm{CO}_{2}$ into carbonic acid and bicarbonate. Microcystis aeruginosa also produces a variety of amino acids, including proline, serine, glycine, and valine (Khan et al., 2018). Microalgae can be a great source of human health bioproducts, which can be attained by mass yield cultivation. Previous research by Bleakley et al. (2017) show 
that the green microalgae Chlorella sp is a rich source of different types of proteins, which have been produced in the market from 2.5 to 7.5 tons/ $\mathrm{Ha} /$ year. Other than that, Nannochloropsis sp is widely used in fish-farm aqua-feed, which have highest protein production $(4-15$ tons/Ha/ year) respectively compared to the soybean and legumes (Al Ghais \& Bhardwaj, 2018).

\section{Algae Mass Production}

The production of microalgae biomass is based on the application of selected species and the commercial value of the microalgae that could be extracted. Microalgae would be the logical source of oils for biodiesel production, which is the most ideal option for $\mathrm{CO}_{2}$ sequestration and numerous other applications (Chisti, 2007; Grobbelaar, 2010; Tredici, 2010). The first fullscale research and production facility for the mass production of microalgae began around 1960 at Trebon in the Czech Republic (Setlik et al., 1970). Furthermore, the mass culture system is applicable in the aquaculture, biofuel and pharmaceutical fields. However, the potential for mass production from algae has indicated that many investors lost a high amount of money due to high-cost maintenance (Tredici, 2010). As emphasised by Grobbelaar (2010), the objective of mass algal production is to identify the highest yields in the shortest possible time or in the high volumetric and area production rates of algal biotechnology in a cost-effective manner. To expand this novel feedstock, research and development are required in several domains, which range from the selection of suitable strains to the optimisation of the different steps required for mass operations, namely biomass production, harvesting and lipid extraction (Pawar \& Gupta, 2017).

\section{Open-pond Culture}

Open ponds are the oldest and the simplest systems for algal culture. Essentially, algae are cultivated under conditions which fulfil the external environment requirement of culture species. Open-pond systems emerged in the 1950s and remain to be widely used in large-scale outdoor microalgal cultivation. The operating costs of open ponds were discussed in terms of mixing, carbon utilisation, nutrients, flocculants, salt disposal, maintenance, labour and the accumulation of photosynthetically produced oxygen (Chisti, 2007). Although various designs have emerged for open-pond systems, three successful major designs are still operating on commercial scales - raceway ponds, circular ponds, and unstirred ponds (Shen et al., 2009).

Some of the key challenges in the productivity of the open-pond system are circulating and mixing the algal cells, nutrients, and $\mathrm{CO}_{2}$ of certain species. Besides, Richmond (2000) identified four constraints for growth in the mass cultivation of algae, which include species selection, genetic manipulation, light utilisation and reactor efficiency. It was also reported that enhanced productivity in terms of biomass, and consequently lipids, could be achieved by enriching the cultures or/and extending the period of light availability. It was inferred from the present results that the incorporation of another effective variable factor was possible, namely paddlewheel speed, on productivity (Moazami et al., 2012). Other than that, the selection of suitable microalgae strains for raw large-scale production by their biomass production, environmental factor, and high growth rates were equally important.

\section{Photobioreactor (PBR)}

Recently, there is prolific research into PBR for efficient and reliable culturing (Breuer et al., 2015). Vargas et al. (2017) found that continuous microalgae production in PBR not only prevents culture contamination, it also controls important process variables. However, PBR also has disadvantages. PBR is a challenging process to reliably scale up (García et al., 2011), and is expensive to construct and operate (Posten, 2009). Furthermore, although microalgae culture production in PBR is also through the batch processing of algae species (Bosma et al., 2014), continuous operation would improve the culture performance as variables could be controlled, 
productivity would be increased, and the risk of contamination could be reduced (Gadkar et al., 2003). However, continuous PBR operation is challenging due to the requirement for largescale units to obtain a feasible product flow. The productivity of the PBRs units also varies due to the scaling up process (García et al., 2011). Meanwhile, feasible PBR design gives the opportunity to use highly reliable mathematical models, as it takes the interactions between several phenomena into account (Fernández et al., 2014).

\section{Culture Media}

In a natural habitat, microalgae obtain all nutrients, minerals, and vitamins from their environment. It was observed in previous studies that the environmental factors of microalgae growth consisted $\mathrm{pH}$, salinity, light, temperature, carbon and nutrients, such as nitrates, phosphates and trace metals (Mata et al., 2010). In a study by Andersen et al. (2005), it was found that several culture media compositions, including freshwater and seawater, were commonly used to produce microalgae. To illustrate, BG-11 medium (blue and green media) or broth media has often been used to culture freshwater green algae and cyanobacteria (Grobbelaar, 2004). Furthermore, it is particularly rich in 1.5 nitrate $\mathrm{NaNO}_{3}$ and exhibits a ratio of wastewater to modified media of 60:1. Similarly, the Bold Basal Medium (BBM) is also used for freshwater algae and cyanobacteria (Boggess, 2014).

A study by Dayananda et al. (2007) compared several culture media, including BG11 and BBM, for the culture of Botryococcus braunii, and it was concluded that BG-11 was the most ideal medium for biomass and hydrocarbon production. In the case of saltwater algae, the modification and formulation of media, including Conway and $\mathrm{f} / 2$ media are normally implemented to produce microalgae monoculture in the laboratory (Xin et al., 2010). These media have been generated based on the basic nutrients needed for algae growth, which are similar to the nutrients needed in the natural habitat condition (Panahi et al., 2019). Based on the research of Lananan et al. (2013), specific growth rate of different genera of algae including Dunaliella sp, Chlorella sp, Chaetoceros sp and Tetraselmis sp were enhanced in $\mathrm{f} / 2$ medium by $72.00 \%, 40.36 \%, 22.40 \%$ and $4.13 \%$ respectively, while Pavlova sp and Isochrysis sp thrived in Conway Medium by $16.39 \%$ and $4.64 \%$ respectively.

\section{NP Ratio}

Algae composition is essential in determining the nutrients for commercial uses in aquaculture industries, such as fish larvae production, livefeed culture and pellet fish feed production (Samat et al., 2020). Nutrient composition, which consists of protein, amino acid, fatty acid and lipid, is highly important for the growth of the aquaculture of fish, marine zooplankton and algae (Craig et al., 2017; Rasdi et al., 2018; Jónasdóttir, 2019). Furthermore, algal growth is related to nitrogen and phosphorus supply in the culture medium (Zhang \& Hu, 2011). Specifically, nitrogen is important in amino acid and protein synthesis, while phosphorus is an important component of phospholipids and in energy metabolism and nucleic acid synthesis for algal growth (Rasdi et al., 2016). Therefore, the low amount of proteins and high carbohydrates in algae cells would be affected by the limitations of N and P (Ganf et al., 1986; Reitan et al., 1994).

The internal composition of marine phytoplankton has been established as 106:16:1, which is represented as a molar ratio for $\mathrm{C}: \mathrm{N}: \mathrm{P}$ known as the Redfield Ratio (Redfield, 1934). However, in the case of freshwater microalgae, the Redfield Ratio becomes an exception instead of being accounted for the N:P molar ratios, which ranged from 8:1 to 45:1 (Hecky et al., 1996; Ptacnik et al., 2010) through a specific species. Furthermore, freshwater microalgae possess the ability to adjust the $\mathrm{N}$ and $\mathrm{P}$ concentration in their biomass in relation to the concentration of the surrounding water (Beuckels et al., 2015; Choi \& Lee, 2015). Furthermore, as the biomass $\mathrm{P}$ accumulation was influenced by the external $\mathrm{P}$ and $\mathrm{N}$ supply, 
while the accumulation of $\mathrm{N}$ was independent of $\mathrm{P}$ (Beuckels et al., 2015). Microalgae growth can be considerably affected by the manipulation of $\mathrm{N}: \mathrm{P}$ ratios in the media culture. Previous research by Rasdi and Qin (2014) indicated that the growth of Nannochloropsis oculata and Tisochrysis lutea increased when the N:P ratio increased from 5:1 to $20: 1$, while the growth was decreased from 20:1 to 120:1. Similarly, the density of Nannochloropsis sp was enhanced when cultured under N:P ratios of 16:1 and 32:1, compared to 64:1 and 80:1 (Mayers et al., 2014). In the case of the biomass production of certain microalgae species, the manipulation of $\mathrm{N}$ and $\mathrm{P}$ ratio should be considered when designing the culture reactor based on the environmental condition. According to Whitton et al. (2016), the selection of species and nutrient concentrations should be considered, which include $\mathrm{N}$ and $\mathrm{P}$ in the biomass and the ability to adapt to external concentrations due to its impacts on the maximum growth and composition rate.

\section{Microalgae and Wastewater}

Microalgae was successfully used in the purification or the treatment of post-culture waters. Wastewater treatment systems, which involve microalgae, present a low-cost and environment-friendly wastewater treatment option compared to conventional processes (Liu et al., 2013). The oxygen produced by microalgae during photosynthesis may reduce the biological oxygen demand in wastewater. Moreover, the eutrophication of nutrients in wastewater, including nitrogen and phosphorus, can be capably removed by microalgae (Lee et al., 2002). Previous researched by Hawrot et al. (2020) mentioned that the concentration of total nitrogen and phosphorus in the wastewater decreased by $87.9 \%$ and $99.1 \%$ after 10 days of treatment with Chlorella minutissima. Similarly, Gao et al. (2016) stated that the total nitrogen and total phosphorus in aquaculture wastewater reduced by $86.1 \%$ and $82.7 \%$ respectively in Chlorella vulgaris. Otherwise, algae wastewater cultivation processes should undergo the same operation as any biological wastewater treatment systems, in which the environmental parameters are considered in the design of algal cultivation processes to ensure high production of lipids and biomass at low cost (Hwang et al., 2016). In a previous study by Khatoon et al. (2016), it is found that the growth and biomass production of Chaetoceros calcitrans, Nannochloropsis maculate and Tetraselmis chuii in aquaculture wastewater was equivalent with the Conway medium. Previous research by Hawrot et al. (2020) also stated that lipid content of Chlorella minutissima growth in $\mathrm{F} / 2$ media compared well with wastewater, which is $51.67 \%$ and $46.37 \%$ dry weight, respectively. Overall, it was indicated that the nutrients in aquaculture wastewater were sufficient for microalgae growth.

\section{The Applications of Microalgae in Environmental Biotechnology}

Microalgae have been used for various applications in environmental biotechnology, in particular, bioremediation, bioassays, and biomonitoring of environmental toxicants and the development of Spirulina platensis in the High Rates Algal Pond System (HRAP) (Phang et al., 2001). Microalgae grown in HRAP have been shown to be beneficial as the treatments for various wastewater, including municipal wastewater (Garcia et al., 2000). Furthermore, over 99\% reduction of phosphate from anaerobically digested starch in factory wastewater occurred in Spirulina platensis grown in HRAP. Moreover, the immobilised microalgae system also enhanced its applicability in the removal of environmental toxicants (Bashan et al., 2010). Meanwhile, Chlorella vulgaris grown in HRAP was found to be useful in the final polishing of textile wastewater before its discharge, especially in the color removal process (Chu et al., 2009). Additionally, it was found in a previous study by Ruiz-Marin et al. (2010) that the immobilised Chlorella vulgaris and Scenedesmus obliquus were effective in the removal of nitrogen and phosphorus from 
urban wastewater, which operated on a semicontinuous mode (Ruiz-Marin et al., 2010).

\section{Common Algae Species Produced by Industries}

Algae are an important group of aquatic organisms for biotechnological exploitation, especially for valuable products, and processes and services in the food, pharmaceutical and aquaculture industries. A wide range of metabolites with various bioactivities produced in algae are yet to be fully exploited (Cardozo et al., 2007). There is a diverse range of algae species, which are widely used around the world, including Spirulina sp and Chlorella sp. It was emphasised by Chu (2012) that the aforementioned algae have been consumed as food supplements (nutraceutical) by humans and as animal feed.

Currently, Spirulina sp is cultured in open ponds for mass and commercial production of biomass as a dietary supplement in several countries, including Thailand, China, United States and India (Soni et al., 2017). It is estimated that 3,000 to 4,000 metric tons of Spirulina $\mathrm{sp}$ is produced worldwide (Belay, 2007). Besides the consumption of food product, Spirulina sp is known for its therapeutic effects on health problems, including diabetes, arthritis, anaemia, cardiovascular diseases and cancer (Sigamani et al., 2016). Moreover, Spirulina $\mathrm{sp}$ is beneficial as a functional ingredient due to its incorporation into various food products to enhance their nutritional qualities and perform therapeutic management of chronic disorders, such as diabetes, hypertension, and heart disease (Mani, 2007).

Chlorella sp is another microalgae species which have been mass cultured for the commercial production of healthy food in the form of pills and powder (Priyadarshani \& Rath, 2012). The first commercial production of this type of microalga was established in Japan in 1961 by Nihon Chlorella Inc. Following this, Chlorella sp factories were developed in several countries including Taiwan, China, and Indonesia, and some 46 large-scale plants had been established in Asia by 1980, producing more than $1000 \mathrm{~kg}$ of Chlorella sp biomass per month (Spolaore et al., 2006). Currently, Chlorella sp products marketed in Malaysia are mainly imported from Japan and Taiwan. The nutritional value of Chlorella $\mathrm{sp}$ is due to their high content of protein, which consist of $51 \%$ to $58 \%$ of dry weight, and carotenoids, with a wide range of vitamins (Becker, 2004).

Another algae species produced on an industrial scale are Nannochloropsis sp and Isochrysis sp. A study by Sirakov et al. (2015) mentioned that Isochrysis sp and Nannochloropsis sp have been used as direct or indirect feed for cultured larval organisms. Indirect means supplying the algae as enrichment for copepod, rotifers and daphnia before fed to the target larval organisms (Rasdi \& Qin, 2018a; Rasdi \& Qin, 2018b; Yuslan et al., 2021). Industrial production of Nannochloropsis sp, known as Nanno 3600 from Reed Mariculture Inc, have been widely used in aquaculture as a booster for increasing yield of rotifer, which is the main diet for shrimp culture (RománReyes et al., 2014). Other than that, Isochrysis $\mathrm{sp}$ also have been used in aquaculture due to their high nutritional value and small 4-6 $\mu \mathrm{m}$ size, which is easily digestible by the larva (Thu et al., 2015). In aquaculture, especially shrimp farming, Algaefeed(C) Isochrysis powder have widely been used as co-feed and showed better result than probiotics, which can prevent the dominance of Vibrio sp, as well as improve egg hatching and larval survival of shrimp culture (Molina et al., 2014).

\section{Conclusion}

Microalgae have proven their high potential in creating new types of organic-based products, including sustainable aquaculture sources and biofuels, bioactive medicinal products and food supplements for humans. Similarly, lowcost microalgae culture may also be feasible as a treatment for wastewater based on the growth requirement of several species of these algae. The upgrade and modification of algae culture techniques and bioproduct technology, such as biofuel, is possible from small scale 
to commercial level, when the challenges and limitations around them are solved. This review has discussed the potential of by-products from microalgae and their extensive applications in bioenergy, aquaculture and pharmaceuticals, which could be achieved through mass-culture production. As a result, an understanding of the growth requirement would be developed, which could be applied to enhance the feasibility and applicability of microalgae for their commercialisation.

\section{Acknowledgements}

The Malaysian Ministry of Higher Education (MOHE) endorsed this study with vote number 53220 (SATREPS-COSMOS), with an aim to develop new ideas and methods for aquaculture growth in Malaysia. The authors declare that there are no conflicts of interest in the formation of this manuscript.

\section{References}

Alabi, A. O., Tampier, Martin \& Bibeau, E. (2009). Microalgae technologies and processes for bioenergy production in british columbia: Current technology, suitability \& barriers to implementation. Final Report submitted to the British Columbia Innovation Council, 1-88.

Al Ghais, S., \& Bhardwaj, V. (2018). Nannochloropsis as potential fish feed. International Journal of Science and Research, 7(12), 278-282.

Aslan, S., \& Kapdan, I. K. (2006). Batch kinetics of nitrogen and phosphorus removal from synthetic wastewater by algae. Ecological Engineering, 28(1), 64-70 390/en6094607

Asfouri, N. Y., Hamed, M. B. B., Abi-Ayad, S. M. E. A., \& Lamara, S. A. C. (2019). The influence of light intensity and photoperiod on the growth of two fresh water green algae Tetranephris brasiliensis and Scenedesmus sp. isolated from estuary. Biotechnology Indian Journal, 15(3), 192 DOI: 10.1016/j. biortech.2012.11.032
Bartley, M. L., W. J. Boeing, B. N. Dungan, F. O. Holguin \& T. Schaub. (2014). pH effects on growth and lipid accumulation of the biofuel microalgae Nannochloropsis salina and invading organisms. Journal of Applied Phycology, 26(3), 1431-14. DOI: 10.1007/ s10811-013-0177-2

Bajpai, R., Prokop, A., \& Zappi, M. (2013). Algal biorefineries: Volume 1: Cultivation of cells and products (Vol. 1). Springer Science \& Business Media.

Barsanti, L., Coltelli, P., Evangelista, V., Frassanito, A. M., Passarelli, V., Vesentini, N., \& Gualtieri P. (2008). Oddities and curiosities in the algal world. In Algal toxins: Nature, occurrence, effect and detection (p. 353-91). Dordrecht: Springer.

Bechet, Q., Laviale, M., Arsapin, N., Bonnefond, H., \& Bernard, O. (2017). Modeling the impact of high temperatures on microalgal viability and photosynthetic activity. Biotechnology Biofuels, 10, 136.

Bechet, Q., Shilton, A., Fringer, O. B., Munoz, R., \& Guieysse, B. (2010). Mechanistic modeling of temperature in outdoor photobioreactors. Environmental Science Technology, 44, 2197-203 DOI: 10.1021/ es903214u

Becker, W. (2004). 18 Microalgae in human and animal nutrition. In Handbook of microalgal culture: Biotechnology and applied phycology (Vol. 312). DOI:10.1002/9780470995280.ch18

Belay, A. (2007). Spirulina (Arthrospira): Production and quality assurance. In Spirulina in human nutrition and health (pp. 15-40). CRC Press.

Beuckels, A., Smolders, E., \& Muylaert, K. (2015). Nitrogen availability influences phosphorus removal in microalgae-based wastewater treatment. Water Research, 77, 98-106.

Bleakley Stephen \& Maria Hayes. (2017). Algal. Extraction, application, and challenges 
concerning production. Foods, 6, 33. Https://doi.org/10.3390/foods6050033.

Boggess, C. D. (2014). Optimization of growth parameters for algal regrowth potential experiments. PhD diss., MS Thesis, The Graduate Faculty of Califonia Polytechnic State University. USA. p.66.

Borowitzka, M. A. (1988). Vitamins and fine chemicals from microalgae. In Borowitzka, M. A., \& Borowitzka, L. J. (ed.), Micro-algal biotechnology (p. 153-96). Cambridge: Cambridge University Press.

Borowitzka, M. A., \& Moheimani, N. R. (2013). Open pond culture systems. In Algae for biofuels and energy (pp. 133-152). Dordrecht: Springer.

Bosma, R., De Vree, J. H., Slegers, P. M., Janssen, M., Wijffels, R. H., \& Barbosa, M. J. (2014). Design and construction of the microalgal pilot facility Algae PARC. Algal Research, 6, 160-169.

Breuer, G., Lamers, P. P., Janssen, M., Wijffels, R. H., \& Martens, D. E. (2015). Opportunities to improve the areal oil productivity of microalgae. Bioresource Technology, 186, 294-302 DOI: 10.1016/j. biortech.2015.03.085

Britton, G., Liaaen-Jensen, S., \& Pfander, H. (2004) Carotenoids handbook. Birkhäuser: Basel, Switzerland. DOI 10.1007/978-30348-7836-4

Campbell, Peter, K., Tom Beer, \& David Batten. (2011). Life cycle assessment of biodiesel production from microalgae in ponds. Bioresource Technology, 102(1), 5056.

Cardozo, K. H., Guaratini, T., Barros, M. P., Falcão, V. R., Tonon, A. P., Lopes, N. P., \& Pinto, E. (2007). Metabolites from algae with economic impact. Comparative Biochemistry and Physiology Part C: Toxicology \& Pharmacology, 146(1-2), 6078.

Carvalho, A. P., Silva, S. O., Baptista, J. M., \& Malcata, F. X. (2011). Light requirements in microalgal photobioreactors: An overview of biophotonic aspects. Applied Microbiology and Biotechnology, 89(5), 1275-1288. DOI: 10.1007/s00253-010$3047-8$

Cheirsilp, B., \& Torpee, S. (2012). Enhanced growth and lipid production of microalgae under mixotrophic culture condition: Effect of light intensity, glucose concentration and fed-batch cultivation. Bio Resource Technology, 110, 510-516. DOI: 10.1016/j. biortech.2012.01.125

Cheng, D. L., Ngo, H. H., Guo, W. S., Chang, S. W., Nguyen, D. D., \& Kumar, S. M. (2019). Microalgae biomass from swine wastewater and its conversion to bioenergy. Bio Resource Technology, 275, 109-122.

Chidambara-Murthy, K. N., Vanitha, A., Rajesha, J., Mahadeva-Swamy, M., Sowmya, P. R., \& Ravishankar, G. A. (2005). In vivo antioxidant activity of carotenoids from Dunaliella salina a green microalga. Life Science, 76, 1382-90 DOI: 10.1016/j. Ifs.2004.10.015

Chisti Y. (2007) Biodiesel from microalgae. Biotechnology Advanced, 25(3), 294-306 DOI: 10.1016/j.biotechadv.2007.02.001

Choi, H. J., \& Lee, S. M. (2015). Effect of the N/P ratio on biomass productivity and nutrient removal from municipal wastewater. Bioprocess and Biosystems Engineering, 38(4), 761-766. DOI: 10.1007/ s00449-014-1317-z

Chu, W. L., See, Y. C., \& Phang, S. M. (2009). Use of immobilised Chlorella vulgaris for the removal of colour from textile dyes. Journal of Applied Phycology, 21(6), 641. DOI:10.1007/s10811-008-9396-3

Chu, W. L. (2012). Biotechnological applications of microalgae. International E-journal of Science Medicine and Education, 6(1), S24-S37.

Converti, A., Casazza, A. A., Ortiz, E. Y., Perego, P., \& Del Borghi, M. (2009). Effect of temperature and nitrogen concentration 
on the growth and lipid content of Nannochloropsis oculata and Chlorella vulgaris for biodiesel production. Chemical Engineering Process, 48, 1146-51.

Covarrubias, Y., Cantoral-Uriza, E. A., CasasFlores, J. S., \& García-Meza, J. V. (2016). Thermophile mats of microalgae growing on the woody structure of a cooling tower of a thermoelectric power plant in Central Mexico., Mexican Journal of Biodiversity, 87, 277-87. https://doi.org/10.1016/j. rmb.2016.04.001

Craggs, R. L. (2001). Wastewater treatment by algal turf scrubbing. Water Science and Technology, 44(11-12), 427-433 https://doi. org/10.2166/wst.2001.0862

Craig, S., Helfrich, L. A., Kuhn, D., \& Schwarz, M. H. (2017). Understanding fish nutrition, feeds, and feeding. Virginia Cooperation Extension, 420-256.

Cuellar-Bermudez, S. P., Aguilar-Hernandez, I., Cardenas-Chavez, D. L., OrnelasSoto, N., Romero-Ogawa, M. A., \& Parra-Saldivar, R. (2015). Extraction and purification of high-value metabolites from microalgae: Essential lipids, astaxanthin and phycobiliproteins. Microbial Biotechnology, 8, 190-209.

Daliry, S., Hallajisani, A., Mohammadi, R. J., Nouri, H., \& Golzary, A. (2017). Investigation of optimal condition for Chlorella vulgaris microalgae growth. Global Journal of Environmental Science and Management. DOI: 10.22034/ GJESM.2017.03.02.010

Das, P., Aziz, S. S., \& Obbard, J. P. (2011). Two phase microalgae growth in the open system for enhanced lipid productivity. Renewable Energy, 36(9), 2524-8.

Dayananda, C., Sarada, R., Rani, M. U., Shamala, T. R., \& Ravishankar, G. A. (2007). Autotrophic cultivation of Botryococcus braunii for the production of hydrocarbons and exopolysaccharides in various media. Biomass and Bioenergy, 31(1), 8793.
De Castro Araujo, S., \& V. N. Tavano Garcia. (2005). Growth and biochemical composition of the diatom Chaetoceros wighamii brightwell under different temperature, salinity and carbon dioxide levels. I. Protein, carbohydrates and lipids. Aquaculture, 246, 405-412.

De-Bashan, L. E., \& Bashan, Y. (2010). Immobilized microalgae for removing pollutants: Review of practical aspects. Bioresource Technology, 101(6), 16111627.

Elfituri, a. M. L. (2018). Growth rate, lipid content and fatty acid profiles of marine and freshwater diatoms in Malaysia. psasir. upm.edu.my. Retrieved http://psasir.upm. edu.my/id/eprint/77322/1/IB\%202018\%20 12\%20-\%20IR.pdf

Fagiri, Y. M. A., Salleh, A., \& El-Nagerabi, S. A. F. (2013). Impact of physico-chemical parameters on the physiological growth of Arthrospira (Spirulina platensis) exogenous strain UTEXLB2340. African Journal of Biotechnology, 12(35).

F. Guihéneuf \& D. B. Stengel. (2013) LC-PUFAenriched oil production by microalgae: Accumulation of lipid and triacylglycerol containing n-3 LC-PUFA is triggered by nitrogen limitation and inorganic carbon availability in the marine haptophyte Pavlova lutheri. Marine Drugs, 11, 42464266.

Fernández, I., Acién, F. G., Berenguel, M., \& Guzmán, J. L. (2014). First principles model of a tubular photobioreactor for microalgal production. Industrial \& Engineering Chemistry Research, 53(27), 11121-11136.

Flynn, K. J. (2020). Enhancing Microalgal Production. Constructing Decision Support Tools Using System Dynamics Modelling. Swansea University. https:// www.enhancemicroalgae.eu/wp-content/ uploads/2019/07/EMA_DST_4.pdf

Gadkar, K. G., Doyle F. J. III, Crowley, T. J., \& Varner, J. D. (2003). Cybernetic model 
predictive control of a continuous bioreactor with cell recycle. Biotechnology Progress, 19, 1487-1497, DOI:10.1021/bp025776d.

Ganf, G. G., Stone, S. J. L., \& Oliver, R. L. (1986). Use of protein to carbohydrate ratios to analyse for nutrient deficiency in phytoplankton. Marine and Freshwater Research, 37(2), 183-197.

Gao, F., Li, C., Yang, Z. H., Zeng, G.-M., Feng, L.-J., Liu, J.-Z., Liu, M., \& Cai, H.W. (2016). Continuous microalgae cultivation in aquaculture wastewater by a membrane photobioreactor for biomass production and nutrients removal. Ecological Engineering, $92,55-61$.

Garcia, J., Mujeriego, R., \& HernandezMarine, M. (2000). High rate algal pond operating strategies for urban wastewater nitrogen removal. Journal of Applied Phycology, 12(3-5), 331-339.

Gardner-Dale, D. A., Bradley, I. M., \& Guest, J. S. (2017). Infuence of solids residence time and carbon storage on nitrogen and phosphorus recovery by microalgae across diel cycles. Water Research, 121, 231-9.

González-Camejo, J., Viruela, A., Ruano, M. V., Barat, R., Seco, A., \& Ferrer, J. (2019). Dataset to assess the shadow effect of an outdoor microalgae culture. Data in brief, 25, 104143. DOI: 10.1016/j. dib.2019.104143

Gouvei a, L., Batista, A. P., Sousa, I., Raymundo, A., \& Bandarra, N. (2008). Microalgae in novel food products. In Konstantinos, N., \& Papadopoulos, P. P. (eds.), Food Chemistry Research Development (p.75-112). New York: Nova Science Publishers.

Grobbelaar, J. U. (2010). Microalgal biomass production: Challenges and realities. Photosynthesis Research, 106(1-2), 135-144. DOI: 10.1007/s11120-010-9573-5

Guedes, A. (2010). Production, extraction and characterization of selected metabolites from microalgae and cynobacteria. Phd
Thesis, Escola Superior de Biotechnologia, Universidade Catolica Portuguesa, Porto.

Guil-Guerrero, J. L., Navarro-Juarez, R., Lopez-Martinez, J. C., Campra-Madrid, P., \& Rebolloso-Fuentes, M. M. (2004). Functional properties of the biomass of three microalgal species. Journal Food Engineering, 65, 511-7.

Gunawan, T. J., Ikhwan, Y., Restuhadi, F., \& Pato, U. (2018). Effect of light Intensity and photoperiod on growth of Chlorella pyrenoidosa and $\mathrm{CO}_{2}$ Biofixation. In E3S Web of Conferences (Vol. 31, p. 03003). EDP Sciences.

Hamilton, M., Haslam, R., Napier, J., \& Sayanova, O. (2014). Metabolic engineering of microalgae for enhanced production of omega-3 long chain polyunsaturated fatty acids. Metabolic Engineering, 22, 3-9.

Hamilton, M. L., Powers, S., Napier, J. A., \& Sayanova, O. (2016). Heterotrophic production of omega-3 long-chain Polyunsaturated fatty acids by tropically converted marine diatom Phaeodactylum tricornutum Marine Drugs.14:53.https:// doi.org/10.3390/md14030053

Hawrot-Paw, M., Koniuszy, A., Gałczyńska, M., Zając, G., \& Szyszlak-Bargłowicz, J. (2020). Production of microalgal biomass using aquaculture wastewater as growth medium. Water, 12(1), 106.

Hayes, K., Shen, K., Howell, A., Kiser, M., Martin, A., \& Lynch, K. (2018). I want algae: The effects of glucose on Picochlorum oklahomensis chlorophyll production and cell density. Journal of Introductory Biology Investigations, 9(2).

Hecky, R. E., Bootsma, H. A., Mugidde, R., \& Bugenyi, F. W. B. (1996). Phosphorus pumps, nitrogen sinks, and silicon drains: plumbing nutrients in the African Great Lakes. The Limnology, Climatology and Paleoclimatology of the East African Lakes. Amsterdam: Gordon and Breach Publishers. 205-223. 
Hemalatha, A., Panneerselvam K., Kalyanasundram G., Chinnadurai S., Perumal A., \& Pitchai S. K. (2014). Effect of nutrients on the growth and biochemical composition of the marine diatom, Chaetoceros simplex (Ostenfeld, 1901). International Journal of Phytopharmacy Research, 5(1), 30-35.

Henriquez, V., Escobar, C., Galarza, J., \& Gimpel, J. (2016). Carotenoids in microalgae. In Stange, C. (ed.), Carotenoids in nature. Subcellular Biochemistry, 79. Cham: Springer.

Hu, Q., Zhang, C. W., \& Sommerfeld, M. (2006). Biodiesel from algae: Lessons learned over the past 60 years and future perspectives. In Annual meeting of the phycological society of America (Juneau). p. 0-41.

Hubble, D. S., \& Harper, D. M. (2001). Impact of light regimen and self-shading by algal cells on primary productivity in the water column of a shallow tropical lake (Lake Naivasha, Kenya). Lakes \& Reservoirs: Research \& Management, 6(2), 143-150.

Huesemann, M. H., Van Wagenen, J., Miller, T., Chavis, A., Hobbs, S., \& Crowe, B. (2013). A screening model to predict microalgae biomass growth in photo bioreactors and raceway ponds. Biotechnology Engineering, 110, 1583-94.

Hwang, J. H., Church, J., Lee, S. J., Park, J., \& Lee, W. H. (2016). Use of microalgae for advanced wastewater treatment and sustainable bioenergy generation. Environmental Engineering Science, 33(11), 882-897.

Ito, T., Tanaka, M., Shinkawa, H., Nakada, T., Ano, Y., Kurano, N., Soga, T., \& Tomita, M. (2012). Metabolic and morphological changes of an oil accumulating trebouxiophycean alga in nitrogen- deficient conditions. Metabolomics, 9(1) https://doi. org/10.1007/s11306-012
Iwamoto, H. (2004). Industrial production of microalgal cell-mass and secondary products major industrial species Chlorella. In Richmond, A. (Ed.), Handbook of microalgal culture (p. 255-63). Oxford: Blackwell.

Iyer, U. M., Dhruv, S. A., \& Mani, I. U. (2007). Spirulina and its therapeutic implications as a food product. Spirulina in Human Nutrition and Health, 51-70. DOI: $10.1201 / 9781420052572$

Jacob-Lopes, E., Scoparo, C. H. G., Lacerda, L. M. C. F., \& Franco, T. T. (2009). Effect of light cycles (night/day) on $\mathrm{CO} 2$ fixation and biomass production by microalgae in photobioreactors. Chemical Engineering and Processing: Process Intensification, 48(1), 306-310.

Jensen, G. S., Ginsberg, D. I., \& Drapeau, M. S. (2001). Bluegreen algae as an immune enhancer and bio modulator. Journal American Nutraceutical Association, 3, 24 30.

Jiang, Y., Nunez, M., Laverty, K. S., \& Quigg, A. (2015). Coupled effect of silicate and nickel on the growth and lipid production in the diatom Nitzschia perspicua. Journal of Applied Phycology, 27(3), 1137-1148.

Jónasdóttir, S. H. (2019). Fatty acid profiles and production in marine phytoplankton. Marine Drugs, 17(3), 151. DOI: $10.3390 / \mathrm{md} 17030151$

Juneja, A., Ceballos, R. M., \& Murthy, G. S. (2013). Effects of environmental factors and nutrient availability on the biochemical composition of algae for biofuels production: A review. Energies, 6, 4607-38.

Jusoh, M., Kasan, N. A., Hashim, F. S., Haris, N., Zakaria, M. F., Mohamed, N. N., ... \& Takahashi, K. (2020). Isolation of freshwater and marine indigenous microalgae species from Terengganu water bodies for potential uses as live feeds in aquaculture industry. International Aquatic Research, 12(1), 7483.DOI:10.22034/IAR(20).2020.671730. 
Kao, C. Y., Chen, T. Y., Chang, Y. B., Chiu, T. W., Lin, H. Y., Chen, C. D., ... \& Lin, C. S. (2014). Utilization of carbon dioxide in industrial flue gases for the cultivation of microalga Chlorella sp. Bioresource Technology, 166, 485-493.

Khalil, Z. I., Asker, M. M., El-Sayed, S., \& Kobbia, I. A. (2010). Effect of $\mathrm{pH}$ on growth and biochemical responses of Dunaliella bardawil and Chlorella ellipsoidea. World Journal of Microbiology and Biotechnology, 26(7), 1225-1231.

Khan, M. I., Lee, M. G., Seo, H. J., Shin, J. H., Shin, T. S., Yoon, Y. H., Kim, M. Y., Choi, J. I., \& Kim, J. D. (2016). Enhancing the feasibility of Microcystis aeruginosa as a feedstock for bioethanol production under the influence of various factors. Biomed Research International, 2016, 4540826.

Khan, M. I., Shin, J. H., \& Kim, J. D. (2018). The promising future of microalgae: Current status, challenges, and optimization of a sustainable and renewable industry for biofuels, feed, and other products. Microbial Cell Factories, 17(1), 36.

Khatoon, H., Banerjee, S., Yusoff, F. M., \& Shariff, M. (2010). Effects of salinity on the growth and proximate composition of selected tropical marine periphytic diatoms and cyanobacteria. Aquaculture Research, 41(9), 1348-1355. doi:10.1111/j.1365-2109.2009. 02423.x

Khatoon, H., Banerjee, S., Syakir Syahiran, M., Mat Noordin, N. B., Munafi Ambok Bolong,A., \& Endut, A. (2016). Re-use of aquaculture wastewater in cultivating microalgae as live feed for aquaculture organisms. Desalination and Water Treatment, 57(60), 29295-29302.

Khoeyi, Z. A., Seyfabadi, J., \& Ramezanpour, Z. (2012). Effect of light intensity and photoperiod on biomass and fatty acid composition of the microalgae, Chlorella vulgaris. Aquaculture International, 20(1), 41-49. https://doi.org/10.1007/s10499-0119440-1
Kim, Z. H., Park, H., \& Lee, C. G. (2016). Seasonal assessment of biomass and fatty acid productivity by Tetraselmis sp. in the ocean using semipermeable membrane photo-bioreactors. JMicrobial Biotechnology, 26,1098-102.

Koller, M., Muhr, A., \& Braunegg, G. (2014). Microalgae as versatile cellular factories for valued products. Algal Research, 6, 52-63 https://doi.org/10.1016/j.algal.2014.09.002

Krzemińska, I., Pawlik-Skowrońska, B., Trzcińska, M., \& Tys, J. (2014) Infuence of photoperiods on the growth rate and biomass productivity of green microalgae. Bioprocess Biosystem Engineering, 37(4), 735-41. https://doi. org/10.1007/s00449013-1044-z

Kumar, D., Dhar, D. W., Pabbi, S., Kumar, N., \& Walia, S. (2014) Extraction and purification of C-phycocyanin from Spirulina platensis (CCC540). Indian of Journal Plant Physiology, 19(2), 184-8. https://doi. org/10.1007/s40502-014-0094-7

Kumar, B. R., Deviram, G., Mathimani, T., Duc, P. A., \& Pugazhendhi, A. (2019). Microalgae as rich source of polyunsaturated fatty acids. Biocatalysis and Agricultural Biotechnology. DOI: 10.1016/j.bcab.2019.01.017

Lananan, F., Jusoh, A., Lam, S. S., \& Endut, A. (2013). Effect of conway medium and $\mathrm{f} / 2$ medium on the growth of six genera of South China Sea marine microalgae. Bioresource Technology, 141, 75-82.

Lardon, L., Hélias, A., Sialve, B., Steyer, J. P., \& Bernard, O. (2009). Life-cycle assessment of biodiesel production from microalgae. Environmental Science Technology, 43,17, 6475-6481.

Lee, K., \& Lee, C.-G. (2002). Nitrogen removal from wastewaters by microalgae without consuming organic carbon sources. Journal Microbiology and Biotechnology, 12, 979985. 
Liang, S., Xueming, L., Chen, F., \& Chen, Z. (2004). Current microalgal health food R\&D activities in China. Hydrobiologia, 512, 45-8. DOI:10.1023/B: HYDR.0000020366.65760.98

Linnewiel-Hermoni, K., Paran, E., \& Wolak, T. (2016). Carotenoid supplements and consumption: Implications for healthy aging. In Molecular Basis of Nutrition and Aging (pp. 473-489). Academic Press. https://doi.org/10.1016/B978-0-12801816-3.00034-0

Liu, J., Ge, Y., Cheng, H., Wu, L., \& Tian, G. (2013). Aerated swine lagoon wastewater: A promising alternative medium for Botryococcus braunii cultivation in open system. Bioresource Technology, 139, 190194.

Luiten, E. E., Akkerman, I., Koulman, A., Kamermans, P., Reith, H., Barbosa, M. J., Sipkema, D., \& Wijfels, R. H. (2003). Realizing the promises of marine biotechnology. Biomolecular Engineering, 20, 429-39. https://doi.org/10.1016/S13890344(03)00074-1

Mallick, N., Bagchi, S. K., Koley, S., \& Singh, A. K. (2016). Progress and challenges in microalgal biodiesel production. Frontiers in Microbiology, 7, 1019.

Martin-Jézéquel, V., Hildebrand, M., \& Brzezinski, M. A. (2000). Silicon metabolism in diatoms: Implications for growth. Journal of Phycology, 36(5), 821840.

Mata, T. M., Martins, A. A., \& Caetano, N. S. (2010). Microalgae for biodiesel production and other applications: A review. Renewable and Sustainable Energy Reviews, 14(1), 217-232.

Mathimani, T., Uma, L., \& Prabaharan, D. (2018). Formulation of low-cost seawater medium for high cell density and high lipid content of Chlorella vulgaris BDUG 91771 using central composite design in biodiesel perspective. Journal of Cleaner Production, 198, 575-586.
Mayers, J. J., Flynn, K. J., \& Shields, R. J. (2014). Influence of the N: P supply ratio on biomass productivity and time-resolved changes in elemental and bulk biochemical composition of Nannochloropsis sp. Bioresource Technology, 169, 588595.doi: 10.1016/j.biortech.2014.07.048.

Maynardo, J. J., Doshi, V. E. E. N. A., Rajanren, J. R., \& Rajasekaran, R. (2015). The optimization of light intensity and drying temperature on lipid content of microalgae Nannochloropsis oculata. J Eng Sci Technol, 112-121.

Moazami, N.,Ashori,A., Ranjbar, R., Tangestani, M., Eghtesadi, R., \& Nejad, A. S. (2012). Large-scale biodiesel production using microalgae biomass of Nannochloropsis. Biomass and Bioenergy, 39, 449-453.

Molina, Grima, E., Belarbi, E. H., Fernández, F. A., Medina, A. R., \& Chisti, Y. (2003). Recovery of microalgal biomass and metabolites: Process options and economics. Biotechnology Advances, 20(78), 491-515.

Molina-Cárdenas, C. A., del Pilar SánchezSaavedra, M., \& Lizárraga-Partida, M. L. (2014). Inhibition of pathogenic Vibrio by the microalgae Isochrysis galbana. Journal of Applied Phycology, 26(6), 2347-2355.

Moller, A. P., Biard, C., Blount, J. D., Houston, D. C., Ninni, P., Saino, N., \& Surai, P. F. (2000). Carotenoid-dependent signals: Indicators of foraging efficiency, immune competence, detoxification ability? Avian and Poultry Biology Review, 11, 137-5.

Morales-Sánchez, D., Martinez-Rodriguez, O. A., \& Martinez, A. (2017). Heterotrophic cultivation ofmicroalgae: Production of metabolites of commercial interest. Journal Chemical Technology and Biotechnology, 92, 925-36. 55.

Muradyan, E. A., Klyachko-Gurvich, G. L., Tsoglin, L. N., Sergeyenko, T. V., \& Pronina, N. A. (2004). Changes in lipid metabolism during adaptation of the Dunaliella salina 
photosynthetic apparatus to high $\mathrm{CO} 2$ concentration. Russian Journal of Plant Physiology, 51(1), 53-62.

Ozkurt I. (2009). Quantifying of safflower and algae for energy. Energy Education Science Technology, 23, 145-51.

Paes, C. R., Faria, G. R., Tinoco, N. A., Castro, D. J., Barbarino, E., \& Lourenço, S. O. (2016). Growth, nutrient uptake and chemical composition of Chlorella sp. and Nannochloropsis oculata under nitrogen starvation. Latin American Journal of Aquatic Research, 44(2), 275-29.

Pahija, E., \& Hui, C. W. (2019). A systematic study on the effects of dynamic environments on microalgae concentration. Algal Research, 42, 101599.

Panahi, Y., Khosroushahi, A. Y., Sahebkar, A., \& Heidari, H. R. (2019). Impact of cultivation condition and media content on Chlorella vulgaris composition. Advanced Pharmaceutical Bulletin, 9(2), 182.

Pandey, J. P., Pathak, N., \& Tiwari, A. (2010). Standardization of $\mathrm{pH}$ and light intensity for the biomass production of Spirulina platensis. Journal of Algal Biomass Utilization, 1(2), 93-102.

Park, H., Jung, D., Lee, J., Kim, P., Cho, Y., Jung, I., Kim, Z-H., Lim, S-M., \& Lee, C-G. (2018). Improvement of biomass and fatty acid productivity in ocean cultivation of Tetraselmis sp. using hypersaline medium. Journal Applied Phycology. DOI: 10.1007/s10811-018-1388-3.

Pawar, S., \& Gupta, S. (2017). Mass production of microalgae in photobioreactors for biodiesel application: Selection, limitations, and optimization. In Optimization and Applicability of Bioprocesses (pp. 211232). Singapore: Springer. https://doi. org/10.1007/978-981-10-6863-8_10

Perez-Garcia, O., Escalante, F. M. E., de-Bashan, L. E., \& Bashan, Y. (2011). Heterotrophic cultures of microalgae: Metabolism and potential products. Water Research,
45(1), 11-36. https://doi.org/10.1016/j. watres.2010.08.037

Peltomaa, E., Johnson, M. D., \& Taipale, S. J. (2017). Marine cryptophytes are great sources of EPA and DHA. Marine Drugs, 16(1), 3. DOI: 10.3390/md16010003

Phang, S. M., Chui, Y. Y., Kumaran, G., Jeyaratnam, S. U. S. I. L. A., \& Hashim, M. A. (2001). High rate algal ponds for treatment of wastewater: a case study for the rubber industry. Photosynthetic Microorganisms in Environmental Biotechnology, 51-76.

Posten, C. (2009). Design principles of photobioreactors for cultivation of microalgae. Engineering in Life Sciences, 9(3), 165-177. https://doi.org/10.1002/elsc.200900003

Priyadarshani, I., \& Rath, B. (2012). Commercial and industrial applications of micro algae: A review. Journal of Algal Biomass Utilization, 3(4), 89-100.

Prokop, A., Bajpai, R. K., \& Zappi, M. E. (Eds.). (2015). Algal biorefineries: Volume 2: Products and refinery design. Springer.

Ptacnik, R., Andersen, T., \& Tamminen, T. (2010). Performance of the Redfield ratio and a family of nutrient limitation indicators as thresholds for phytoplankton $\mathrm{N}$ vs. $\mathrm{P}$ limitation. Ecosystems, 13(8), 1201-1214.

Raehtz, K. (2009). Challenges and advances in making microalgae biomass a cost efficient source of biodiesel, MMG 445 Basic Biotechnology Journal, 5(1), 37-43.

Rao, A. R., C. Dayananda, R. Sarada, T. R. Shamala \& G. A. Ravishankar. (2007). Effect of salinity on growth of green alga Botryococcus braunii and its constituents. Bioresource Technology, 98, 560-564.

Rasdi, N. W., \& Qin, J. G. (2014). Effect of $\mathrm{N}: \mathrm{P}$ ratio on growth and chemical composition of Nannochloropsis oculata and Tisochrysis lutea. Journal of Applied Phycology, 27(6), 2221-2230. doi:10.1007/s10811-014-0495-z 
Rasdi, N. W., Qin, J. G., \& Li, Y. (2016). Effects of dietary microalgae on fatty acids and digestive enzymes in copepod Cyclopina kasignete, a potential live food for fish larvae. Aquaculture Research, 47(10), 3254-3264.

Rasdi, N. W., Suhaimi, H., Yuslan, A., Sung, Y. Y., Ikhwanuddin, M., Omar, S. S., ... \& Yusoff, F. M. (2018). Effect of mono and binary diets on growth and reproduction of cyclopoid copepod. Aquaculture, Aquarium, Conservation \& Legislation, 11(5), 1658-1671.

Rasdi, N. W., \& Qin, J. G. (2018a). Copepod supplementation as a live food improved growth and survival of Asian seabass Lates calcarifer larvae. Aquaculture Research, 49(11), 3606-3613.

Rasdi, N. W., \& Qin, J. G. (2018b). Impact of food type on growth, survival and reproduction of the cyclopoid copepod Cyclopina kasignete as a potential live food in aquaculture. Aquaculture International, 26(5), 1281-1295.

Redfield, A. C. (1934). On the proportions of organic derivatives in sea water and their relation to the composition of plankton. James Johnstone Memorial Volume, 176-192.

Reitan, K. I., Rainuzzo, J. R., \& Olsen, Y. (1994). Effect of nutrient limitation on fatty acid and lipid content of marine microalgae 1. Journal of Phycology, 30(6), 972-979.

Renaud, S. M., D. L. Parry, T. Luong-Van, C. Kuo, A. Padovan \& N. Sammy. (1991). Effect of light intensity on the proximate biochemical and fatty acid composition of Isochrysis sp. and Nannochloropsis oculata for use in tropical aquaculture. Journal of Applied Phycology 3, 43-53.

Richmond, A. (2000). Microalgal biotechnology at the turn of the millennium: A personal view. Journal of Applied Phycology, 12(3), 441-451.
Riebesell, U., Revill, A. T., Holdsworth, D. G., \& Volkman, J. K. (2000). The effects of varying $\mathrm{CO} 2$ concentration on lipid composition and carbon isotope fractionation in Emiliania huxleyi. Geochimica et Cosmochimica Acta, 64(24), 4179-4192. https://doi. org/10.1016/S0016-7037(00)00474-9

Román-Reyes, J. C., Castañeda-Rodríguez, D. O., Castillo-Ureta, H., BojórquezDomínguez, R., \& de Oc, G. A. R. M. (2014). Population dynamics of rotifer Brachionus ibericus isolated from shrimp ponds, fed with different diets. Latin American Journal of Aquatic Research, 42(5), 11591168. https://doi.org/10.3856/vol42-issue5fulltext-19

Ruiz-Marin, A., Mendoza-Espinosa, L. G., \& Stephenson, T. (2010). Growth and nutrient removal in free and immobilized green algae in batch and semi-continuous cultures treating real wastewater. BioSource Technology, 101(1), 58-64.

Sathasivam, R., Radhakrishnan, R., Hashem, A., \& Abd_Allah, E. F. (2019). Microalgae metabolites: A rich source for food and medicine. Saudi Journal of Biological Sciences, 26(4), 709-722. https://doi. org/10.1016/j.sjbs.2017.11.003

Sahu, A., Pancha, I., Jain, D., Paliwal, C., Ghosh, T., Patidar, S., \& Mishra, S. (2013). Fatty acids as biomarkers of microalgae. Phytochemistry, 89, 53-58.

Samat, N. A., Yusoff, F. M., Rasdi, N. W., \& Karim, M. (2020). Enhancement of Live Food Nutritional Status with Essential Nutrients for Improving Aquatic Animal Health: A Review. Animals, 10(12), 2457.

Serejo, M. L., Morgado, M. F., García, D., González-Sánchez, A., Méndez-Acosta, H. O., \& Toledo-Cervantes, A. (2020). Environmental resilience by microalgae. In Microalgae cultivation for biofuels production (pp. 293-315). Academic Press. https://doi.org/10.1016/B978-0-12817536-1.00019-9 
Setlík, I., Šust, V., \& Málek, I. (1970). Dual purpose open circulation units for large scale culture of algae in temperate zones. I. Basic design considerations and scheme of a pilot plant. Algological Studies. Supplement Volumes, 111-164.

Shanab, S. M., Hafez, R. M., \& Fouad, A. S. (2018). A review on algae and plants as potential source of arachidonic acid. Journal of Advanced Research, 11, 3-13.

Shen, Y., Yuan, W., Pei, Z. J., Wu, Q., \& Mao, E. (2009). Microalgae mass production methods. Transactions of the ASABE, 52(4), 1275-1287.DOI: 10.13031/2013.27771

Shetty, P., Gitau, M. M., \& Maróti, G. (2019). Salinity stress responses and adaptation mechanisms in Eukaryotic Green Microalgae. Cells, 8(12), 1657.

Show, P. L., Tang, M. S. Y., Nagarajan, D., Ling, T. C., Ooi, C-W., \& Chang, J-S. (2017). A holistic approach to managing microalgae for biofuel applications. International Journal Molecular Science, 18(1), 215. https://doi.org/10.3390/ijms18010215.

Sigamani, S., Ramamurthy, D., \& Natarajan, H. (2016). A review on potential biotechnological applications of Microalgae. Journal of Applied Pharmaceutical Science, 6(8), 179-84.

Simionato, D., Basso, S., Giacometti, G. M., \& Morosinotto, T. (2013). Optimization of light use efficiency for biofuel production in algae. Biophysical Chemistry, 182, 7178 .

Singh, S. P., \& Singh, P. (2015). Effect of temperature and light on the growth of algae species: A review. Renewable and Sustainable Energy Review, 50, 431-44. https://doi.org/10.1016/j.rser.2015.05.024

Sirakov, I., Velichkova, K., Stoyanova, S., \& Staykov, Y. (2015). The importance of microalgae for aquaculture industry. Review. International Journal of Fisheries and Aquatic Studies, 2(4), 81-84.
Solovchenko, A. E., Khozin-Goldberg, I., Didi-Cohen, S., Cohen, Z., \&Merzlyak M. N. (2008). Effects of light intensity and nitrogen starvation on growth, total fatty acids and arachidonic acid in the green microalga Parietochloris incise. Journal Applied Phycology, 245-251. http://doi. org/10.1007/s10811-007-9233-0

Soni, R. A., Sudhakar, K., \& Rana, R. S. (2017). Spirulina from growth to nutritional product: A review. Trends in Food Science \& Technology, 69, 157-171.

Spolaore, P., Joannis-Cassan, C., Duran, E., \& Isambert, A. (2006). Commercial applications of microalgae. Journal of Bioscience and Bioengineering, 101(2), 8796.

Suh, I. S., \& Lee, C. G. (2003). Photobioreactor engineering: Design and performance.

Biotechnology and Bioprocess Engineering, 8(6), 313-321.

Thu, N. T. H., Anh, H. T. L., Hoang, M. H., Kim, D. D., \& Hong, D. D. (2015). Study on biological characteristics of a newly isolated Vietnamese strain of microalga Isochrysis galbana Parke for utilizing as live aquaculture feed. Russian Journal of Marine Biology, 41(3), 2032111.

Tredici,M.R.(2010). Photobiology ofmicroalgae mass cultures: Understanding the tools for the next green revolution. Biofuels, 1(1), 143-162.

Valdés, F. J., Hernández, M. R., Catalá, L., \& Marcilla, A. (2012). Estimation of $\mathrm{CO}_{2}$ stripping $/ \mathrm{CO}_{2}$ microalgae consumption ratios in a bubble column photobioreactor using the analysis of the $\mathrm{pH}$ profiles. Application to Nannochloropsis oculata microalgae culture. Bioresource Technology, 119, 1-6.

Vargas, S., Gómez-Pérez, C. A., \& Espinosa, J. (2017). A method for the design of a continuous microalgae culture photobioreactor in series with recirculation system. CT\&F-Ciencia, Tecnología $y$ Futuro, 7(1), 101-116. 
Wen, Z.-Y., \& Chen, F. (2003). Heterotrophic production of eicosapentaenoic acid by microalgae. Biotechnology Advances, 21(4), 273-294. doi:10.1016/s07349750(03)00051

Whitton, R., Le Mével, A., Pidou, M., Ometto, F., Villa, R., \& Jefferson, B. (2016). Influence of microalgal $\mathrm{N}$ and $\mathrm{P}$ composition on wastewater nutrient remediation. Water Research, 91, 371-378.

$\mathrm{Wu}$, H. (2016). Effect of different light qualities on growth, pigment content, chlorophyll fluorescence, and antioxidant enzyme activity in the red alga Pyropia haitanensis (Bangiales, Rhodophyta). Biomed Research International, 2016, 7383918.

Xin, L., Hong-ying, H., Ke, G.,\& Ying-xue, S. (2010). Effects of different nitrogen and phosphorus concentrations on the growth, nutrient uptake, and lipidaccumulation of a freshwater microalga Scenedesmus sp. Bioresource Technology, 101(14), 54945500 .

Xu, L., Weathers, P. J., Xiong, X. R., \& Liu, C. Z. (2009). Microalgal bioreactors: Challenges and opportunities. Engineering in Life Sciences, 9(3), 178-189.

Ye, C.P., Zhang, M.C., Yang, Y.F., \& Thirumaran, G. (2012). Photosynthetic performance in aquatic and terrestrial colonies of Nostoc flagelliforme (Cyanophyceae) under aquatic and aerial conditions. Journal of
Arid Environment, 85, 56-61. https://doi. org/10.1016/j.jaridenv.2012.03.023

Ying, K., Zimmerman, W. B., \& Gilmour, D. J. (2014). Effects of CO and $\mathrm{pH}$ on growth of the microalga Dunaliella salina. Journal of Microbial and Biochemical Technology, 6(3), 167-173.

Yuslan, A., Najuwa, S., Hagiwara, A., Ghaffar, M. A., Suhaimi, H., \& Rasdi, N. W. (2021). Production performance of Moina macrocopa (Straus 1820) (crustacea, cladocera) cultured in different salinities: the effect on growth, survival, reproduction, and fatty acid composition of the neonates. Diversity, 13(3), 105.

Zeng, X., Danquah, M. K., Chen, X. D., \& Lu, Y. (2011). Microalgae bioengineering: From $\mathrm{CO}_{2}$ fixation to biofuel production. Renewable Sustainable Energy Rev., 15, 3252-60.

Zhang, D., Wan, M., del Rio-Chanona, E. A., Huang, J., Wang, W., Li, Y., \& Vassiliadis, V. S. (2016). Dynamic modelling of Haematococcus pluvialis photoinduction for astaxanthin production in both attached and suspended photo bioreactors. Algal Research, 13, 69-78.

Zhang, Q., \& Hu, G. (2011). Effect of nitrogen to phosphorus ratios on cell proliferation in marine micro algae. Chinese Journal of Oceanology and Limnology, 29(4), 739745. 